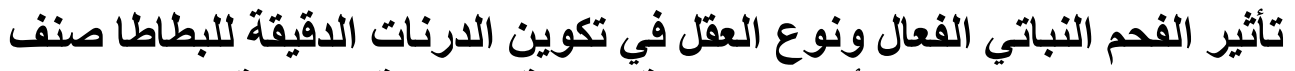

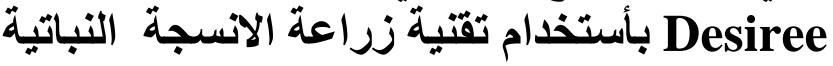

\title{
In vitro Effect of Activated Charcoal and microcutting type on microtuberization of potato $\mathrm{CV}$. Desiree
}

\author{
موسى محمـ حمزة \\ المعهد التقني / المسيب / العراق
}

المستخلص

زرعت النموات الخضرية المأخوذة من درنات البطاطا صنف Desiree بطول 0.3- 0.5 ملم بعد أن عقمت



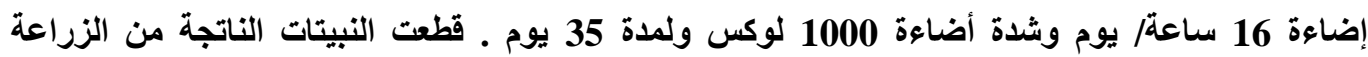


وسط MS Mاص بتكوين الارنات الدقيقة يحتوي على 10\% سكروز مع تراكيز مختلفة من الفحم النباتي الفعال 0.0 ، 0.5 ، 1.0 ، 1.5 ، 2.0 ، 2.5 و 3.0 غم / لتر .

أظهرت النتائج أن للتاخل بين الفحم النباتي الفعال ونوع العقل المزروعة تأثيراً معنوياً على الصفات المدروسة فقد تفوقت العقل القاعدية عند التركيز 3.0 غم/ لتر فحم في أعطاء اعلى معدل وزن وحجم وعدد

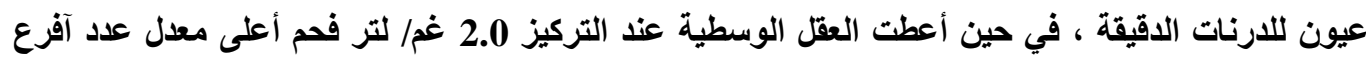
خضرية.

\section{Abstract:}

Tips of sprouts $(0.3-0.5 \mathrm{~mm})$ of Desiree potato sterilized and cultured on proliferation media. The cultures were incubated for 35 days at 16 hours photoperiod at $25 \pm 2{ }^{\circ} \mathrm{C}$ under 1000 loux light intensity. In vitro - proliferated shoot were cut at $1-2 \mathrm{~cm}$ into three types of microcuttings (i.e. apical, subapical and basal) and cultured onto MS media supplimented with 10\% sucrose for microtuberization. Activated Charcoal treatments 0.0, 0.5, 1.0, 1.5, 2.0, 2.5 and $3.0 \mathrm{gm} / \mathrm{l}$ were added to the microtuberization media .The weight, size and eyes number cultured of microtubers were significantly increased when basal microcuttings cultured on microtuberization media supplimented with 3gm / charcoal while $2 \mathrm{gm} / \mathrm{l}$ charcoal with the subapical cuttings resulted in high proliferation rate. 
[7] ـ أتبعت هذه التقنية بنجاح في الكثير من الدول المتقدمة حيث ان 50\% من الدول الاوربية تنتج تقاويها بهذه التقنية [8] فالجهد المبذول والكلفة القلبلة في انتاج التقاوي بأستخدام هذه التقنية كان عاملا مشجعأ للعديد من الباحثين لتطوير اساليب استخدامها ، وقد تعددت وسائل الانتاج من الدرنات الدقيقة الى انتاج الثتلات [9] ـ وقد أظهرت

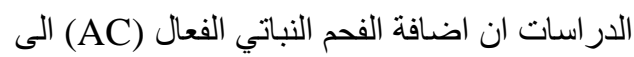
الاوساط الغذائية الصلبة بتر اكيز 0.5 - 3\% يمكن

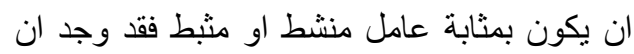
اضافة الفحم النباتي الفعال الى الوسط الغذائي قد ادى الى تحفيز النمو وتمايز الاعضاء

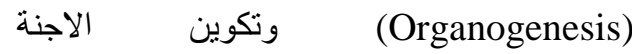
في العديد من الانواع (Embryogenesis) النباتية [10] ـ كما ان اضافة الفحم النباتي الى هن الى الوسط الصلب بسبب اسوداد الوسط الغذائي وبذلك

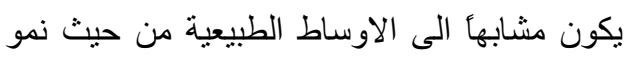
الجذور والمدادات في الظلام ، كذلك يؤدي الى لى لهات ادمصاص Adsorption المركبات السامة التي ولي تعيق النمو للجزء النباتي المزروع كما ان الفحم النباتي الفعال يدمص منظمات النمو النباتية من

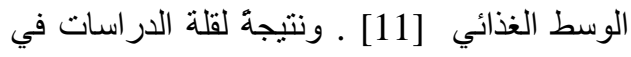
تحديد كمية الفحم النباتي الفعال (AC) في الاوساط

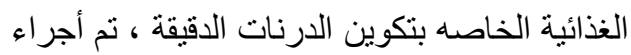

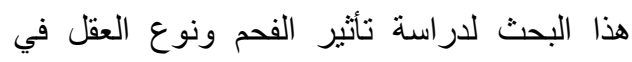
تكوين الدرنات الدقيقة لصنف البطاطا Desiree .

لوكس وبعد إسبوعين من الحضانة أصبحت النموات الخضرية النامية بطول ( 8 بونين من 10 ) سم. فصلت أطر اف الأفرع من البر اعم الخضرية النامية بطول (1 2) سم وغسلت بالماء الجاري لمدة 30

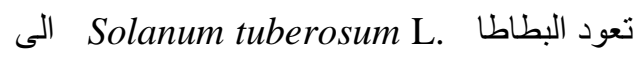
العائلة الباذنجانية Solanaceae وتعدّ البطاطا رابع محصول اقتصادي في العالم بجانب الحنطة و الرز والذرة الصفراء [1] ـ كما انها نأتي في المرتبة الثانية من حيث الاستهلاك البثري كونها تشكل الغذاء الرئيسي للكثير من سكان العالم ومصدرأ هامَ للكثير من العناصر الغذائية ، فضلاً عن احتوائها على نسبة عالية من النشأ والبروتين [2] ، كما تحتوي على الاحماض الامينية المختلفة وبالاخص اللايسين (Lysine) الذي تفتقر الية محاصيل الحبوب ، اضافة الى الاحماض العضوية و الفيتامينات [3] ـ تكثر البطاطا اما جنسيأ بو اسطة البذور و هذه الطريقة غير متبعة في انتاج التقاوي وذللك بسبب الانعز الات الور اثية التي تحدث لكون المحصول مفتوح التلقيح وبذللك لايمكن الحصول على نفس مو اصفات الصنف عند اكثاره [4] ، الا ان تقنية زراعة البذور تستخدم بشكل واسع في

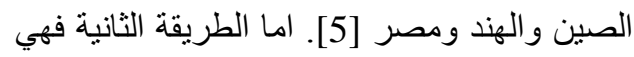
اللاجنسية بواسطة الدرنات التي هي سيقان منتفخة تنمو تحت سطح التربة ، ومع طرق الاكثار الخضري, غالباً ما تتعرض النباتات للاصابه بالفطريات و البكتريا والفيروسات وبذلك تكون النتيجة هي كمية حاصل قليلة وذات نوعية رديئة


الآنسجة في تربية واكثار نباتات البطاطا بهدف الحصول على تقاوي ذات مواصفات مرغوبة وخالية من المسببات المرضية وبالذات الفايروسية

\section{المـواد وطرائق العمل}

حضنت درنات البطاطا صنف Desiree في صناديق فلين تحتوي على بيتموس ورمل بنسبة


وفترة إضاءة 16 ساعة/ يوم وشدة أضاءة 1000 
25×150 ملم، عدلت الدالة الهيدروجنية (PH) الى

5.7 ثم حضنت الزروعات في غرفة النمو (صورة

1) تحت درجة حرارة 25 مْ ـ 2 و وفترة أضاءة

16 ساعة / بوم وشدة أضاءة 1000 لوكس ولمدة درة درة

35 يوم ، أخذت النبيتات (Plantlets) بعد ان لندة اطناعة

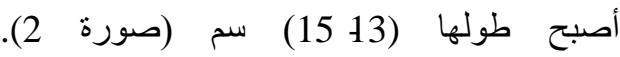

دقيقة ثم عقمت بمحلول كلوريد الزئبق $\mathrm{HgCl}_{2}$ بتركيز 0.06\% ولمدة 5 دقائق داخل جهاز التعقيم الهو ائي الطبقي (Laminar air flow cabinet) ثم قصرت الأفرع بطول (0.3 - 0.5 سم) وزرعت على الوسط الغذائي MS [12] يحتوي على غغم/لتر فحم مع اضافة \%3\% سكروز و7.0 غم/لتر آكار (Agar) داخل انابيب الاختبار قياس

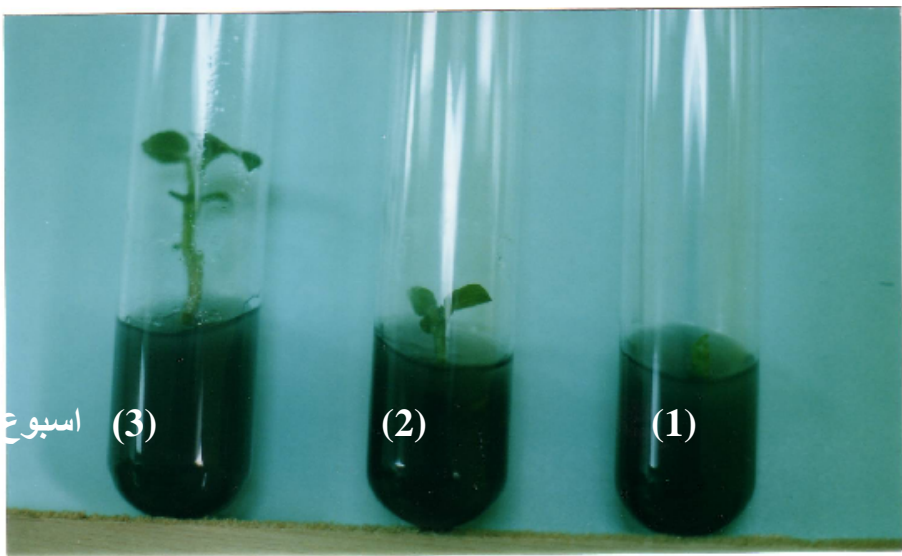

صورة رقم (1): توضح مراحل نمو اطراف الآفرع في وسط MS يحتوي على الفحم النباتي الفعال

من (1) 1 1) اسبوع من الزراعة

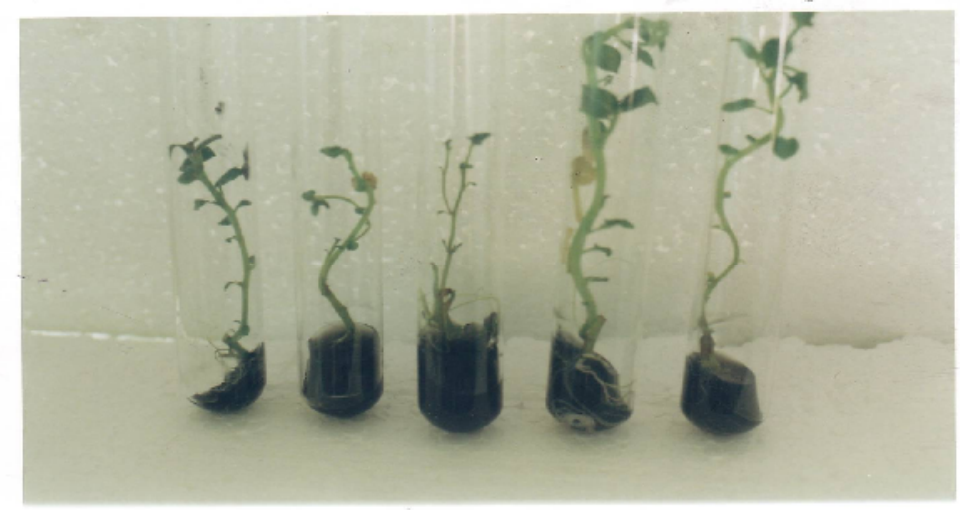

صورة رقم (2) : مراحل نمو اطراف الآفرع من الاسبوع الرابع حتى الاسبوع السادس

سعة 250 ملم تحتوي على وسط MS خاص بتكوين الدرنات الدقيقة مضافا اليه 10\% سكروز مسع تر اكيز مختلفة مـن الفحم (0.0 ، 0.5 ، 1.0 ، 1.0 1.5 ، 2.0 ، 2.5 و 3.0 غم/ لتر) بواقع خمسة
ووضعت في اطباق بتري داخل جهاز التعقيم الهوائي الطبقي وأزيلت الجذور، ثم أخذت منها العقل القاعدية ، العقل الوسطية و العقل الطرفية بطول (1 2) سم وزرعت داخل أوعية زجاجية 
(ملغم) و عدد العيون/ درنة وعدد الدرنات الدقيقة ، و عدد الافرع الخضرية/ عقلة أمـا حجم الدرنات فقد أستخدمت القدمة (Vernier) لتحديد أقطار ها (ملم) [13] وبو اقع 5 مكرارت/ معاملة ولجميع الصفات المدروسة ـ تم تحليل البيانات إحصائيا بأستخدام التجارب العالمية وفق التصميم العثوائي الكامل CompletelyRandomized ) CRD (Design ) ثم قورنت المتوسطات عند اقل فرق

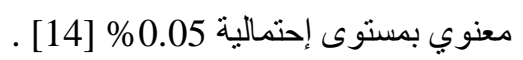

عقل/ دورق ونقلت الى غرفة النمو وحضنت على درجة حرارة 18 م $1 \pm$ وفترة إضاءة 8 ساعة/ يوم ولمدة 812 أسبوع لتحفيز وتكوين الدرنات الدقيقة ، تكونت الأفرع الخضرية بعد أسبوع من التحضين (صورة 3) ـ بدأت عملية تكوين الدرنات الدقيقة بعد اسبوعين من الزراعة وتكاملت بعد شهرين (صورة رقم 4) حصدت الدرنات بواسطة الملاقط بنط و المشارط وغسلت بالماء الجاري وتركت في

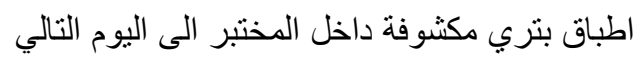
لكي تجف ثم أخذت القراءات لأوزان الدرنات النتبائسج:

\section{1}

بشكل قوي يضمن تدفق عالي للسكروز الذي يتحلل الى سكريات بسيطة ، تستخدم في بناء النشأ

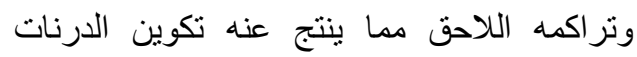

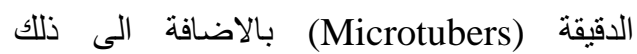
فالسكروز يعتبر مصدر جيد للكاربون حيث بسهل تمثيله وتحويله الى النشأ اللازم لتكوين الدرنات الاقيقة [16] ـ كما يعتبر السكروز منظما ازموزياً للوسط الغذائي المستخدم ، فالتراكيز العالية من

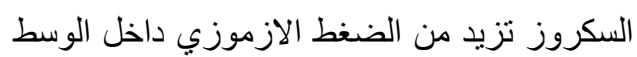

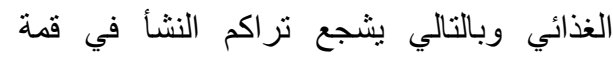

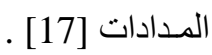

توضح نتائج الجدول (1) أن الفحم النباتي الفعال له

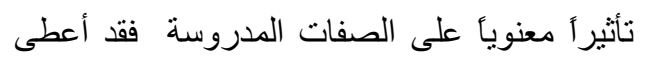
التركيز 3 غم/لتر أعلى معدل وزن وحجم وعدد عيون للارنات الدقيقة وبذلك تفوقت معنويأ على اعلى التراكيز الاخرى ، بينما لم يظهر الفحم تأثنير معنوي في عدد الدرنات الدقيقة ، وقد يعود السبب ألى أن عملية تكوين الدرنات الدقيقة تعتمد بالاساس على كمية السكروز المضافة الى الوسط

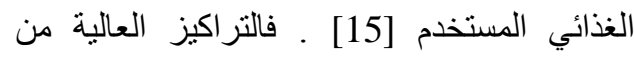
السكروز قد تخلق حاله فسلجية عند قمة المدادات ينتج عنها تكوين منطقة تجمع النواتج الايضية

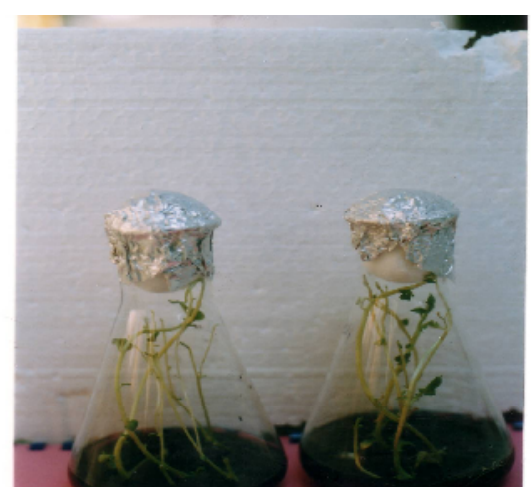

صورة رقم (3): توضح تكوين الافرع على العقل النامية داخل وسط MS حاو على الفحم 


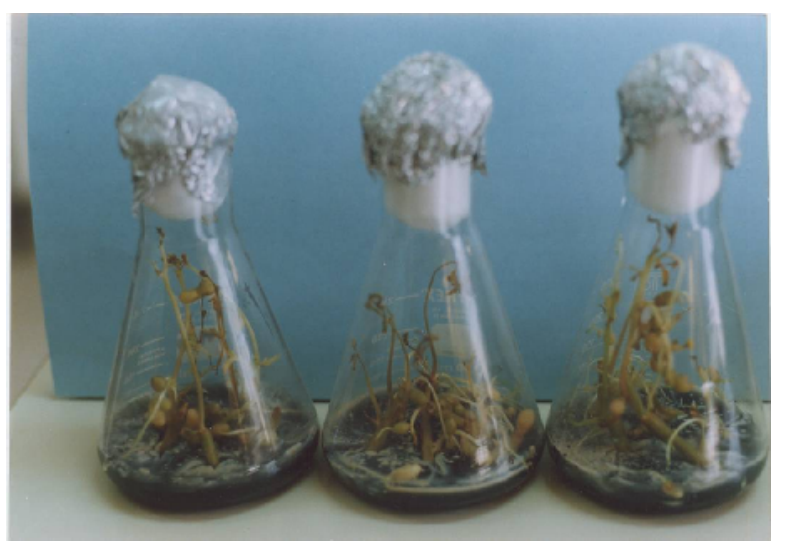

صورة رقم (4): توضح تكوين الدرنات الدقيقة على العقل النامية داخل الوسط الغذائي

المرستيمية الغنية بالاوكسينات ، التي ترتبط مع

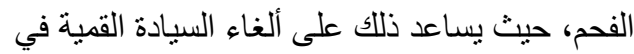
النبيتات وبالتالي يدفع بادئات البر اعم الموجودة في لئي

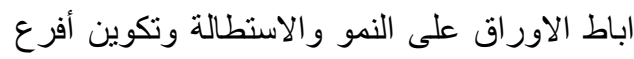
جديدة [18] ـ كما أن نبيتات البطاطا المزروعة

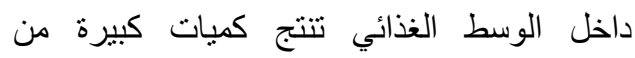
السايتوكاينينات ، وعند انتقال هذه الهرمونـات داخل النباتات ، تعمل على ألغاء السـيادة القمية وتحفيز البراعم الابطية على النمو وتـكويـن

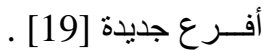

يلاحظ من الجدول نفسه بأن الفحم النباتي الفعال

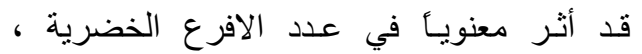

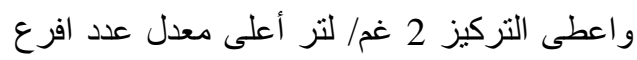
خضرية بلغ 5.9 فرع/عقلة في حين أختلفت التر اكيز الاخرى معنوياً فيما بينها وتفوقت جميعها

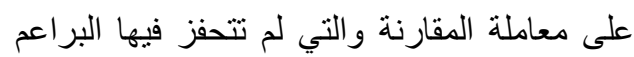
الابطية الموجودة على العقل النامية داخل الوسط

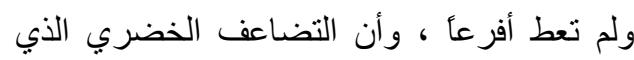
حصل في اعداد الافرع، كان نتيجة لاختلال

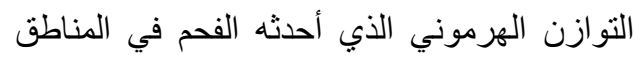

جدول (1): تأثير تراكيز مختلفة من الفحم النباتي على معدلات الصفات المدروسة

\begin{tabular}{|c|c|c|c|c|c|}
\hline الخضرية/ عقدة الافرع & الدقيقة / علدة الدرنات & عدد العيون /درنة & الدقيقة / ملم & وزن الدقيقة/ ملفن & تركيز الفحم \\
\hline 1.0 & 3.4 & 3.0 & 2.6 & 146.4 & 0.0 \\
\hline 2.8 & 3.2 & 3.4 & 3.3 & 208.7 & 0.5 \\
\hline 4.2 & 3.1 & 3.8 & 3.9 & 313.0 & 1.0 \\
\hline 4.6 & 3.3 & 4.5 & 4.6 & 375.6 & 1.5 \\
\hline 5.9 & 3.2 & 5.1 & 5.4 & 509.8 & 2.0 \\
\hline 5.2 & 3.1 & 5.2 & 5.6 & 511.3 & 2.5 \\
\hline 5.0 & 3.3 & 6.2 & 6.7 & 531.4 & 3.0 \\
\hline 0.6 & م.غ & 0.4 & 0.8 & 16.2 & L S D 0.05 \\
\hline
\end{tabular}




\section{2 تأثير نوع العقل في تكوين الارنات الاقيقة على الوسط الغذائي}

الآخرى ، حيث أعطت العقل الوسطية أعلى معدل عدد درنات دقيقة و أفر عأ خضرية بلغت 3.9 و4.5 على التوالي وقد تفوقت معنوياً على بقية أنواع

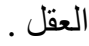

كما يلاحظ من الجدول نفسه إن العقل الطرفية هي

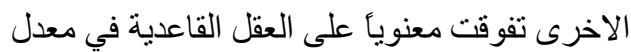
عدد الافرع الخضرية وفي عدد الدرنات الدقيقة. وقد يعزى السبب في ذلك الـى إن العقل الطرفيـة والوسطية قد أعطت عقدأ أكثر بلغت 1012 عقدة

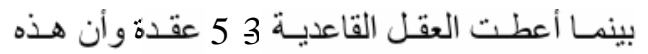
الزيـادة في عدد العقد سـاعد على أعطـاء أفرعـا خضرية و عدد درنات دقيقة بنسب أعلى من العقل القاعدية ـ و هذه النتائج تنتف مـع [21] حيث وجد أن العقل القاعدية بعد تكوين الدرنات الدقيقة عليها تميـل الـى النضـج المبكر وتنهي دورة حياتهـا بعد شهرين من الزراعة ، بينمـا تستمر العقل الوسطية

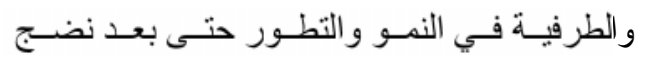

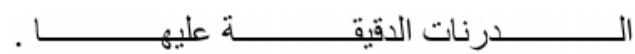

تنشير نتائج الجدول (2) الى وجود فروقات معنوية بين انواع العقل المزروعة لصنف البطاطا Desiree تفوقت العقل القاعدية المزروعة على الوسط الغذائي MS الخاص بتكوين الدرنات الدقيقة على بقية انواع العقل الآخرى حيث أعطت اعلى معدل وزن وحجم و عدد عيون/ درنة بلغت 445.9 ملغم ، 5.9 ملم ، 6.2 عين/ درنة على التوالي ، وقد وند يعزى السبب في ذلك الى ان العقل القاعدية تكون ذات عمر فسلجي اكبر من العقل الاخرى ، وهذه النتائج تتفق مع [20] حيث وجد ان العقل القاعدية ذات العمر الفسلجي الاعلى تعطي درنات دقيقة ذات وزن وحجم وعدد عيون اكثر وذللك لاحتو ائها على منشط تكوين الدرنات الدقيقة بكميات اعلى من العقل الاخرى و المأخوذة من نف النبيتة (Plantlet) الخضرية للعقل القاعدية مما أدى إلى إنخفاض ملحوظ في عدد الدرنات الدقيقة مقارنة بالعقل

جدول ( 2 ): تأثير نـوع العقل لصنف البطاطا Desiree على معدلات الصفات المدرسة خارج الجسم الحي

\begin{tabular}{|c|c|c|c|c|c|}
\hline الخضرية /عقلة & الاقيقة/ عقد الدرناتة & 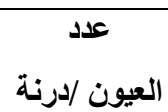 & حجم الارنات & وزن الدرقية /ملغن & نوع العقلّ \\
\hline 2.9 & 2.3 & 6.2 & 5.9 & 445.9 & القاعدية \\
\hline 4.5 & 3.9 & 4.0 & 4.0 & 331.4 & الوسطية \\
\hline 3.5 & 3.0 & 3.4 & 3.3 & 234.2 & الطرفية \\
\hline 0.4 & 0.2 & 0.3 & 0.5 & 10.2 & $\mathrm{LSD}_{0.05}$ \\
\hline
\end{tabular}

3 معنوياً في الوسط الغذائي الحاوي على 3غم/لنز أظهرت نتائج الجدول (3) وجود تأثثر معنوي فحم وأعطت أعلى معدل وزن وحجم و عدد عيون للتناخل بين مستويات الفحم النباتي الفعال المضافة للارنات الاقيقة بلغت على التوالي 789.3 ملغم الى الوسط الغذائي الخاص بتكوين الدرنات الدقيقة ،9.8 ملم ، 8.4 عين في حين أختلفت التراكيز

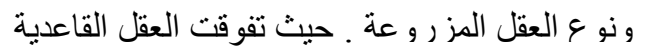


وتثير نتائج الجدول نفسة الى وجود فروقات معنوية بين أنواع العقل المزروعة في معدل عدد

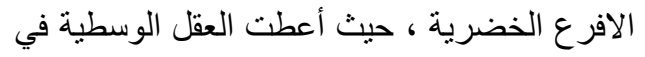

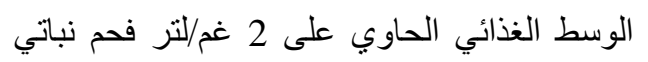
فعال أعلى معدل عدد أفرع خضرية بلغ 6.4 فرع الغراتي في حين أعطت العقل القاعدية والعقل الطرفية لنفس الوسط أفرع خضرية بلغت 3.8 و5.2 فرع اعن وكان

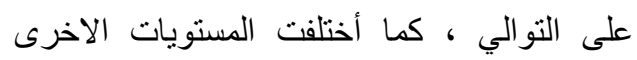

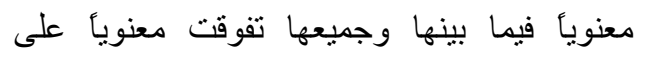

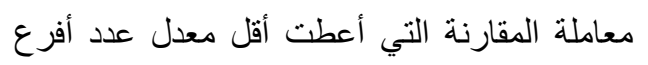
خضرية بلغ فرع واحد ولجميع انواع العقل

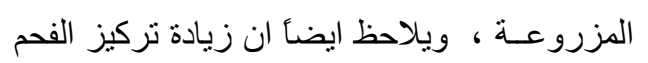
النباتي الفعال داخل الوسط الغذائي الخاص بتكوين

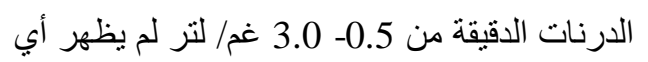
ضرر فسلجي على الجزء النباتي المزروع وان اضافة الفحم الى الوسط يجعل الوسط الغذائي معتما وبالتالي يوفر بيئة ملائمة لعملية نكوين الدرنات

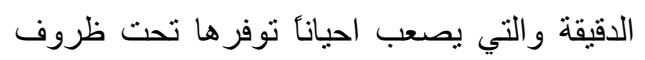

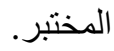

الاخرى معنوياً فيما بينها وجميعها تفوقت على معاملة المقارنة التي أعطت اقل معدل وزن وحجم وعدد عيون للارنات الدقيقة بلغت 185.9 ملغم ، 3.2 ملم ،3.4 عين على التو الي. وقد يعزى السبب لقدي في ذلك الى أن الفحم النباتي الفعال يدمص المواد الفينولية المؤكسده من الوسط الغذائي المستخدم

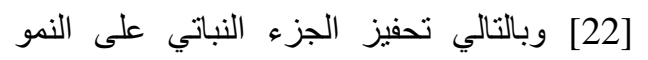
بصورة أفضل . كما يلاحظ من الجدول نفسه عدم

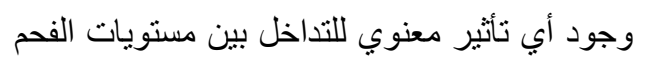
النباتي الفعال المضافة الى الوسط الغذائي ونوع العقل المزروعة في عدد الدرنات الدقيقة وقد أعطى لئى

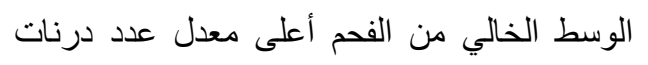

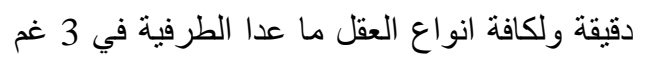
فحم/ لتر، وذلك يعود الى أن عملية تكوين الدرنات الدقيقة خارج الجسم الحي هي عملية فسلجية تتداخل فيها المواد المغذية كالسكروز ومنظمات النمو ، بالاضافة الى الظروف البيئية المحيطة

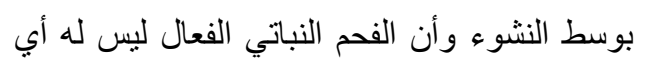
دور فسلجي في زيادة عدد الدرنات الدقيقة ولجميع

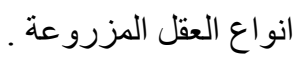

جدول (3): تاثير التداخل بين الفحم النباتي الفعال ونوع العقل على معدل الصفات المدروسة للبطاطا صنف

Desiree

\begin{tabular}{|c|c|c|c|c|c|c|}
\hline علد الخضرية / عقرعة & الدقيقة / عقلة الدرنات & عدد العيون & 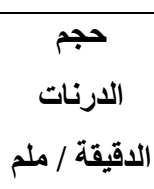 & وزن الدقيقة / ملفم & نوع العقل & غركيز الفحم \\
\hline 1.0 & 2.6 & 3.4 & 3.2 & 158.9 & القاعدية & \multirow{3}{*}{0.0} \\
\hline 1.0 & 4.2 & 3.0 & 2.6 & 150.2 & الوسطية & \\
\hline 1.0 & 3.4 & 2.6 & 2.2 & 130.3 & الطرفية & \\
\hline 2.1 & 2.6 & 4.2 & 4.0 & 256.2 & القاعدية & \multirow{3}{*}{0.5} \\
\hline 3.8 & 4.0 & 3.0 & 3.4 & 201.8 & الوسطية & \\
\hline 2.6 & 3.2 & 3.0 & 2.6 & 168.3 & الطرفية & \\
\hline 3.6 & 2.4 & 5.0 & 4.8 & 362.6 & القاعدية & \\
\hline
\end{tabular}




\begin{tabular}{|c|c|c|c|c|c|c|}
\hline 5.2 & 3.8 & 3.4 & 3.8 & 336.5 & الوسطية & \multirow[t]{2}{*}{1.0} \\
\hline 3.8 & 3.2 & 3.0 & 3.2 & 240.1 & الطرفية & \\
\hline 3.8 & 2.2 & 5.7 & 6.2 & 488.3 & القاعدية & \multirow{3}{*}{1.5} \\
\hline 5.8 & 4.0 & 4.4 & 4.4 & 347.7 & الوسطية & \\
\hline 4.2 & 3.0 & 3.4 & 3.4 & 290.9 & الطرفية & \\
\hline 3.8 & 2.2 & 6.8 & 7.8 & 680.1 & القاعدية & \multirow{3}{*}{2.0} \\
\hline 6.4 & 3.8 & 4.8 & 4.8 & 469.2 & الوسطية & \\
\hline 5.2 & 3.2 & 3.8 & 3.8 & 380.2 & الطرفية & \\
\hline 3.4 & 2.3 & 6.8 & 7.7 & 683.1 & القاعدية & \multirow{3}{*}{2.5} \\
\hline 6.1 & 3.7 & 5.3 & 5.1 & 475.6 & الوسطية & \\
\hline 5.0 & 3.3 & 3.9 & 3.9 & 382.4 & الطرفية & \\
\hline 3.2 & 2.2 & 8.4 & 9.8 & 789.3 & القاعدية & \multirow{3}{*}{3.0} \\
\hline 5.2 & 3.6 & 5.6 & 5.4 & 483.2 & الوسطية & \\
\hline 4.2 & 3.8 & 4.8 & 5.0 & 321.8 & الطرفية & \\
\hline 0.3 & م.غं & 0.6 & 0.5 & 8.2 & \multicolumn{2}{|c|}{ L S D 0.05} \\
\hline
\end{tabular}

تحسـين الأنتـاج النبـاتي ـ الهيئـة العربيـة للطاقـة

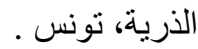

5. Rashid, M. H., S .Akhter, M. Elias, M.G. Rasul, and M.H. Kabir. (1993). Seeding tubers for ware potato production .Influence of size and plant spacing .Asian Potato J. Vol. 3.

6. Djurdjina, R., M. Milinkovie, and D. Milosevie. (1997). In vitro propagation of potato (Solanum tuberosum L.) .Acta Horticulturae .462:959-963.

7. Das, A., S. S .Gosal, J. S. Sidhuand, and H. S. Dhaliwal. (2001).

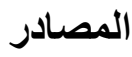

1. Jones, R. L. (1994). Gibberelline: Their physiological role. Agricultural Review of Plant Physiology. 24: 571 598.

2. Hawkes, J.G.(1990). The potato: Evolution, Biodiversity and genetic resources. Beethoven. Printing. London p. 259.

3. حسـن، احمـــ عبــ المـنعم . (1999). انتـاج البطاطا ، الدار العربية للنشر والتوزيع. جمهورية

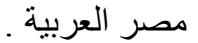

(1995) ـ أهداف وطرق تربية

الطفر ات فـي النباتــات خضــرية التكـاثز ــ وقـائع

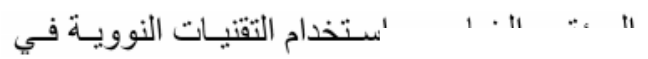


15. Avigad,G., and P. M . Dey. (1997).

Carbohydrate metabolism: storage carbohydrates. In: Plant Biochemistry, PP 143 - 203. (Eds P. M. Dey and

J.B. Harborne) Academic press. London UK.

16. Appeldoorm, N.J.G., De S.M. Bruijn, E.A.M. Koot - Gronsveld, R.G.F Visser, D.Vreugdenhil, and L.H.W.Van Derplas. (1997).

Developmental change of enzymes involved in sucrose to hexose phosphate conversion during early tuberization of potato.Planta 202:202226.

17. Ross, A. H., H.V. Davies, M. R. Burch, and J. E.Bryan. (1994). Developmental changes in carbohydrate content and degrading enzymes in tuberising stolons of potato (Solanum tuberosum L.) Physiologia Plantarum .90: 748 - 756.

18. Marschner, H., B.Sattelmacher, and F.Bangerth. 1989. Growth rate of potato tuber and endogenous contents of indole acetic acid and abscisic acid. Physiol Plant .60:16 - 20.

19. Alejar, A.A. and L.R. Gonzal. 1986. Variation in plant hormones III. The effect of light or darkness on hormone levels in buds of sprouting potato tubers. PH I L. AGR. 69: 35-36. 20. Bhojwani, S.S. (2001). Role of Tissue Culture in Plant Industry.
In vitro mutagenesis and production of agronomically useful potato variants. Mutation and Breeding News Letter Issue. No. 45.

8. Najjar, K. F. (1993). Commercialization of the patented microtuber multiplication system of potato. The second Arab conference on perspective of Modern Biotechnology. Amman, Jordon.

9. Hassan, S.M., T. Jan, and I. Khan. (1990). Production of potato through tissue culture techniques. Sarhad of Agric , VoL.6,No.4

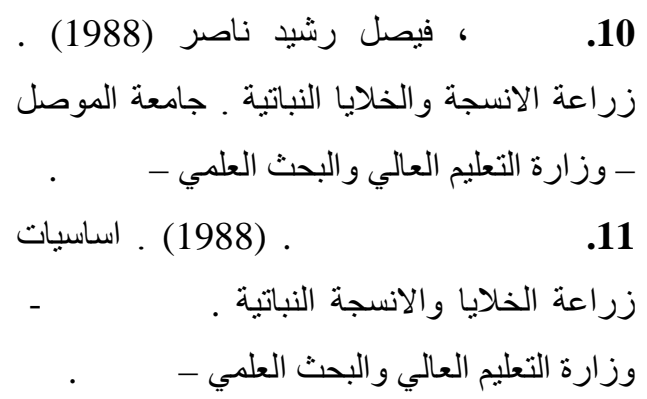

12. Murashige, T., and F. Skoog. 1962 .A revised medium for rapid growth and bioasseys with tobacco tissue cultures. Physiologia Plantarum.15: $473-497$.

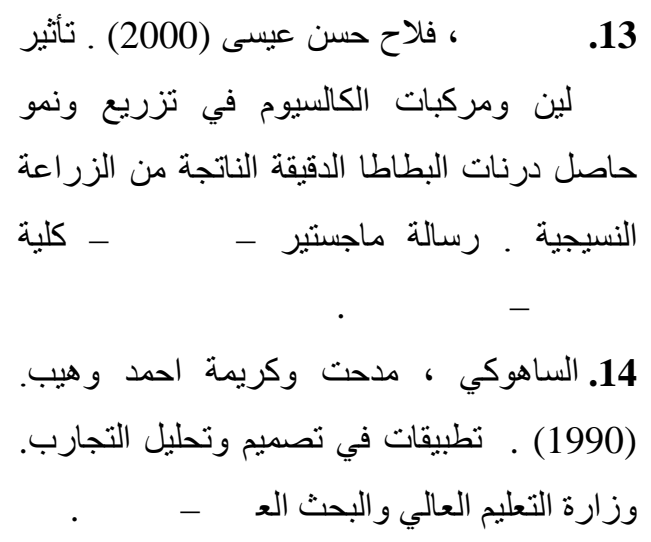


22. Fridborg, G., M. Pedersen, L. Department of Botany, University of Landstrom and T. Eriksson. (1978). Delhi, India.

The effect of activated charcoal on

21. Hones, M.S. (2003). The effect of tissue culture adsorption of metabolites sucrose concentration on inhibiting morphogensis - Physiol Plant. 34-104. micropropagation of potato (Solanum tuberosum L.) . Am. J. Potato Res. 80 : $103-115$. 